\title{
The Role of Physical Activity in the Prevention and Rehabilitation of Breast Cancer
}

\author{
Christine Graf $^{a} \quad$ Klara Brixius $^{a} \quad$ Freerk Baumann $^{b} \quad$ Andre Ahr ${ }^{c} \quad K^{\prime a u s ~ S c h u ̈ l e ~}{ }^{b}$ \\ a Institute for Cardiology and Sports Medicine, German Sport University, \\ ${ }^{b}$ Institute for Rehabilitation, German Sport University, Köln, \\ c Department of Gynaecology, Johann-Wolfgang-Goethe University Hospital, Frankfurt/M., Germany
}

\section{Key Words}

Exercise - Breast cancer - Primary prevention . Rehabilitation

\section{Summary}

The inverse relationship between physical activity and breast cancer risk has been confirmed by several epidemiological and case control studies. But the use of different test methods makes it difficult to come to a unified statement and a conclusive evaluation as to how much exercise is required. However, risk reduction of breast cancer seems to be between 30 and $40 \%$ amongst women who engage in daily and leisure time activities. Exercise has marked effects on many different systems of the human body that may reduce cancer risk, e.g. endogenous hormones, energy balance, body composition, immune function, DNA repair and antioxidant defense. These effects vary according to type, frequency, intensity, and duration of physical activity. The American Cancer Society recommends to engage in moderate to vigorous physical activity at least $4 \mathrm{~h}$ a week to reduce the risk of breast cancer. In addition to the apparent role of exercise in primary prevention of breast cancer, there is growing interest in and evidence for its usefulness during and after breast cancer treatment. Exercise may reduce the probability of recurrence and enhance survival. The mechanisms are supposed to be similar to those occurring in primary prevention. In addition, the effects on psychosocial factors and fatigue improve quality of life after the diagnosis. The greatest benefit occurred in women who performed moderate physical activity 3-5 h per week.

\author{
Schlüsselwörter \\ Körperliche Aktivität · Brustkrebs · Primärprävention · \\ Rehabilitation
}

\section{Zusammenfassung}

Die inverse Beziehung zwischen körperlicher Aktivität und dem Risiko, an Brustkrebs zu erkranken, konnte durch eine Vielzahl epidemiologischer und Fall-KontrollStudien belegt werden. Allerdings ist naturgemäß die Untersuchung von Bewegung/Sport methodisch erschwert, hinzu kommt die Nutzung verschiedener Testmethoden und unterschiedlicher Kollektive. Daher ist eine endgültige Aussage, wie viel Sport notwendig ist, erschwert. Insgesamt findet sich jedoch eine Risikoreduktion um etwa 30 bis $40 \%$ bei aktiven gegenüber inaktiven Frauen. Die zugrundeliegenden Effekte von körperlicher Aktivität sind vielfältig und noch nicht endgültig aufgedeckt, und betreffen z.B. Hormone, Energiebilanz, Körperkomposition, Immunsystem, DNA-Reparatur und antioxidative Wirkung. Diese Wirkmechanismen sind von der Sportart, Häufigkeit, Intensität und Dauer des Sporttreibens abhängig. Die American Cancer Society empfiehlt aktuell, zur Reduktion des Brustkrebsrisikos mindestens 4 Stunden wöchentlich moderate bis intensive Aktivität zu betreiben. Neben der Rolle der körperlichen Aktivität in der Primärprävention wächst das Interesse und die Studienlage zu Bewegung in der Therapie von Krebserkrankungen. Möglicherweise kann Sport die Rezidivrate senken und das Überleben steigern. Auch hier werden die gleichen Mechanismen zugrundegelegt wie in der Primärprävention. Zusätzlich beeinflusst körperliche Aktivität psychosoziale Faktoren und das FatigueSyndrom und steigert die Lebensqualität. Den größten Nutzen scheinen Frauen zu haben, die pro Woche 3-5 Stunden aktiv sind.

\begin{tabular}{ll}
\hline KARGER & @ 2006 S. Karger GmbH, Freiburg \\
Fax +497614520714 & Accessible online at: \\
$\begin{array}{l}\text { E-mail Information@Karger.de } \\
\text { www.karger.com }\end{array}$ & www.karger.com/brc
\end{tabular}

Dr. med. Dr. Sportwiss. Christine Graf Institut für Kreislaufforschung und Sportmedizin Deutsche Sporthochschule Köln

Carl-Diem-Weg 6, 50933 Köln, Germany Tel. +49 221 49-825230, Fax -12906

E-mail C.Graf@dshs-koeln.de 


\section{Introduction}

Breast cancer is the most common cancer diagnosed among women. The risk of breast cancer is increased by several factors including sedentary lifestyle. The International Agency for Research on Cancer estimates that $25 \%$ of breast cancer are due to physical inactivity and obesity [1]. Risk, however, can be reduced by changes in lifestyle, e.g. well-balanced energy intake, avoiding obesity and staying physically active. First reports on the inverse relationship between cancer prevention and exercise date back to the 1920s [2, 3]. Since than, more than 200 observational epidemiologic studies have examined this association trying to work out adequate recommendations.

The analysis of exercise and physical activity is complicated and dependent upon practiced methods, such as questionnaires, observations and fitness tests. Varying results are the consequence of the different procedures used to measure exercise and activity. Questionnaires and interviews are always dependent upon the subjective view of the participants. A more objective method is the measurement of fitness, which, on the other hand, is genetically determined. To draw final conclusions, the retrospective designs always have to be taken into consideration. As the nature of sport medicine is such that double-blind tests are impossible, the significant findings are mostly based upon epidemiological tests. With respect to breast cancer, a risk reduction of between 30 and $40 \%$ was shown [4]. The analysis of fitness and physical performance is deemed to be more objective. Evenson et al. [5] studied the relationship between fitness/performance, overweight and tumor mortality in general. For men, the lowest mortality rate was in the fittest group. For women, no difference was found. Taking the Body Mass Index (BMI) values into consideration produced no significant change in the results. This study contradicted earlier results from Blair et al. [6], in which a better fitness value was associated with lower tumor mortality for both genders.

Physical activity, however, also plays an important role in cancer rehabilitation. Besides positive psychosocial effects (reduced fatigue, less depressions, better quality of life etc.) [7], survival seems prolonged and the risk of recrudescence and death may be reduced [8]. In this overview, the current data regarding physical activity and breast cancer risk, underlying mechanisms, the role of exercise during and after cancer treatment, and recommendations are presented.

\section{Prevention}

Physical activity is defined as bodily movement produced by skeletal muscles resulting in a measurable form of energy expenditure [9]. This includes all daily, recreational/leisure time, occupational, and household activities. Today, the evidence for a relationship between exercise and breast cancer is nearly as strong as that found for colon cancer, but data are not consistent [10]. The inconsistent outcomes observed among studies can be attributed to methodological differences in assessing physical activity mentioned above. In addition, type of exercise, study population etc. vary across these studies. The risk reductions ranged from 0 up to $70 \%$, on average between 30 and $40 \%$ [11]. The first National Health and Nutrition Examination Study (NHANES I) showed amongst pre- and postmenopausal women a higher breast cancer risk factor of 1.7 for inactive women compared to their active counterparts [12]. In 2 important women's studies - the Nurses' Healthy Study and the Women's Health Study - the authors found a comparable risk reduction of approximately $20 \%$ in active women $[13,14]$. According to occupational physical activity, Thune et al. [15] showed in a Norwegian cohort study involving 25,624 women that those who were regularly physically active in job and leisure time had a $33 \%$ lower risk of becoming ill compared to women who were less active. The trend was much clearer among premenopausal women.

The Heidelberg study by Steindorf et al. [16] merely showed that a high level of daily activity provided effective prevention. In a later randomized study involving 1,800 women the effect of exercise upon cancerogenesis was investigated, showing a clear inverse relationship between physical activity and a reduced risk of breast cancer. However, the level of exercise has to be high, light physical exercise does not reduce the risk [17].

There are no studies directly analyzing what intensity and duration of exercise is necessary to decrease breast cancer risk. Increasing evidence suggests that longer duration and greater intensity of physical activity are associated with a reduced risk of breast cancer. Many studies suggest a dose-response interrelation. At the present time, the best advice to reduce the risk of breast cancer is to engage in moderate to vigorous physical activity at least $4 \mathrm{~h}$ a week.

\section{Mechanisms}

The mechanisms of exercise and physical exertion in the human body are complex, and, especially regarding their role in cancer prevention, not completely clarified. The effects on sex and metabolic hormones, BMI and body composition, energy balance and the immune system are under discussion.

\section{Sex Hormones}

Female athletes often have a reduced plasma concentration of sex hormones, especially estradiol, a late menarche, an early menopause and a higher occurrence of anovulatory cycles [18]. These are generally assumed to be a result of low body weight and a latent caloric deficit [19]. With increasing age, the levels of free estradiol and testosterone become higher and increase the risk of breast cancer [20]. It is therefore important to motivate this age group to become or stay active. 
Additionally, in abdominal obesity with a higher triglyceride and insulin concentration a lower concentration of sex hormone binding globulin (SHGB) and a consecutive higher concentration of free estradiol is found [21]. However, the actual influence of moderate exercise on the levels of estrogen and progesterone and their metabolism, and hence the potential breast cancer risk, still has to be further investigated.

\section{Metabolism Hormones}

Another hormonal parameter which is under discussion in connection with breast cancer, is the insulin-like growth factor 1 (IGF-1). The Nurses' Health Study showed an association between the IGF-1 plasma concentration of premenopausal women and the risk of breast cancer [22]. Inactive persons have a higher concentration of IGF-1, possibly as a result of the positive energy balance [22]. The mechanism with which IGF-1 stimulates carcinogenesis is not clear. Proteinkinase C is under discussion as the mediator, an enzyme in the cell membrane, which is found in higher concentrations in breast cancer cells than in healthy mammary tissue. Proteinkinase $\mathrm{C}$ is activated by estrogen and can be arrested by anti-estrogens, such as tamoxifen [22]. Therefore, this mechanism could also play a role in alterations to the estrogen induced by sport.

In addition, hyperinsulinemia may increase the risk of breast cancer. Hyperinsulinemia is associated with a higher bioavailability of IGF-1 in the target tissue and a reduction in the hepatic production of the relevant binding proteins (IGFBP-1 and -3). Therefore, a higher risk of breast cancer exists when there is a higher concentration of IGF-1 and/or a reduction in the IGFBP-3 concentration $[23,24]$.

\section{Energy Balance}

It is undisputed that physical activity together with the total caloric balance influence weight and body composition and have a positive effect on the metabolic system, especially with regards to carbohydrate and fat metabolism. Inactivity and overweight seem to promote the onset of bowel, breast and prostate cancer as well as cancer of the uterus. This is, amongst other reasons, justified by the negative influence on the endogenous hormone metabolism, which ultimately benefits the onset of cancer [25]. As already stated, a low body fat content seems to be associated with low estrogen levels [19]. Conversely, a lack of physical exercise and the high energy intake that is often associated therewith lead to obesity, especially in persons who are genetically predisposed. Obesity or an androgenic body fat distribution seem to play a role in the genesis of breast cancer [15]. The metabolic processes in fatty tissue lead to an increase in free fatty acids and $\mathrm{TNF} \alpha$ blood concentrations [26]. The enzyme aromatase in fatty tissue enables an increase in free estradiol and in the occurrence of precancerous lesions in the mammary tissue [20].

A well-balanced diet has a multitude of effects upon endocrine organs and the metabolism. Pre- and postmenopausal women on a fat-reduced diet show a decline in the estrogen concentration. A fiber-rich diet also seems to reduce estrogen levels [27]. As well as influencing estrogen levels, diet also seems to effect the levels of IGF-1 [28]. A fiber-rich diet for overweight women leads to a reduction in free IGF-1, an increase in insulin sensitivity, and, therefore, to a higher concentration of SHGB [29]. Hence, as well as affecting body composition, diet seems to play a role in the genesis of breast cancer via the actions of endocrine factors and associated effects.

\section{Immune System}

The immune system is a complex system, comprising a large body of cell types and cytokines. Exercise has different acute or chronic effects upon all parts of the immune system mainly due to epinephrine, cortisol release and its effect on cytokines such as interleukin 6, but the significance of its role in cancer risk reduction remains unclear [30,31]. The most sensitive reaction to epinephrine release within the leukocyte subpopulation is that of the natural killer (NK) cells, showing the highest relative dose-dependent increase (150-300\% [32]). The number of cytotoxic $\mathrm{T}$ cells due to high intensity exercise increases between 50 and $100 \%$.

In the first hours after physical activity, a reduction in those subpopulations can be observed. This concerns mainly T cells, especially NK cells, regulatory T cells and cytotoxic T lymphocytes. The level of monocytes and macrophages remains low even a few days after intensive or long-term physical exercise. This effect, however, does not occur as a result of moderate activities [33]. It is believed that this effect could be attributed to the release of cortisol due to exercise.

As well as the changes in cell count, cell activity and humoral defense systems are also influenced by physical activity. Under intensive physical stress, the activity of NK cells increases by $40-100 \%$ followed by a decrease to $25-35 \%$ below the initial level [32]. This does not occur after moderate activity [30]. In terms of macrophages, moderate intensity seems to enhance phagocytic activity and cytotoxity [19]. In conclusion, the available evidence indicates that moderate exercise can improve the immune system, but its role in cancer risk reduction remains unclear.

\section{Therapy}

Interest is increasing as to whether physical activity can be helpful during and after cancer therapy. Exercise is an effective intervention to improve quality of life, cardiorespiratory fitness, physical functioning and fatigue in breast cancer patients and survivors [34]. The illness, and the side effects of the treatment, have negative effects upon physical performance, fitness and body composition as well as mental disposition. Physical activity prevents or diminishes the loss of fitness and helps to increase muscular performance and improve quality of life [35]. It can reduce symptoms such as nausea, fatigue, depression, fear and pain [36]. 
Only a small number of studies have investigated the effects of physical activity during tumor therapy. In most cases, the activity consisted of moderate endurance training, such as cycling or walking 3 times a week for 20-30 min. A meta-analysis performed by Schmitz et al. [37] showed that physical activity during treatment was well tolerated, and that fitness and discomfort improved. Dimeo et al. [38] observed after an aerobic training program a reduction in the duration of hospitalization, neutropenia and thrombocytopenia, and severity of pain and diarrhea in patients after high-dose chemotherapy including about $50 \%$ breast cancer patients in the intervention and control group.

Studies on the effects of physical activity after a therapy (on average 3-5 days a week of cycling or walking for 20-30 min over a period of approximately 3 months) showed a reduction in possible side effects [39]. Thorsen et al. [40] investigated the effect of physical activity on cardiorespiratory fitness (VO2max) and the quality of life of 111 tumor patients after chemotherapy (lymphoma, tumors of the reproductive system; age 18-50 years). After 14 weeks of training, an improvement in fitness was found, but there was no change in the quality of life compared to a control group.

Thune and Smeland [41] carried out a systematic review of the effects of physical activity during and after treatment of cancer patients. They included 38 studies most of which showed an improvement in the quality of life and a reduction in fatigue. No indication was found relevant to survival. The limitations were small groups and short observation and intervention periods. In contrast, a current analysis presented by the Nurses' Health Study [8] shows that regular participation in sports (e.g. 3-5 h of walking per week) seems to raise the chances of surviving breast cancer.

Further controlled, prospective studies need to be designed, planned and executed so that a conclusive answer can be provided as to what can safely be recommended for which tumor type. Nevertheless, McTiernan [42] points out the basic influence that physical activity has upon the cardiovascular system and the metabolism, and its long term positive effect for survivors.

\section{Recommendations and Conclusion}

There currently is a large number of epidemiological data examining the relationship between physical activity and breast cancer. Although physically active persons are also likely to live a healthier lifestyle, the observed associations are unlikely to be due to these habits. The inverse association between physical activity and the risk of breast cancer continues to be observed after adjustment to potential confounders, such as BMI, age at menarche, menopausal status, parity, age at first birth, breast feeding, family history, use of oral contraceptives and hormone therapy [43].
Up to now, it has not been conclusively clarified which type, intensity, frequency and duration of exercise should be practiced. The current goal is to achieve a minimum of $30 \mathrm{~min}$ of physical activity on at least 5 days a week [44]. Many studies have shown a so-called dose-response relationship [4], but it has also been demonstrated that physical activity does not have to be practiced in 20-30-min blocks but can also be carried out in 10-min sessions. An active lifestyle is the first step towards physical activity and therefore makes the return to active sports/training easier. The Harvard Alumni Study established the benchmark figure of an extra 1,000 kcal that need to be burned by any form of activity to prevent colon cancer [45]. It is recommended to use stairs instead of elevators, to walk or cycle to work, to take a 10-min break at work and go for a walk. These activities should be continuously incremented until the above mentioned daily $30 \mathrm{~min}$ of activity have been reached [44]. The Division of Prevention Oncology in Canada, however, recommends moderate to vigorous training for 30-45 min on an almost daily basis [46].

For rehabilitation, endurance training is recommended in most cases [47]. The greatest benefit occurred in women who performed moderate physical activity $3-5 \mathrm{~h}$ per week. The roles of moderate and adequate resistance training, such as prevention of muscle loss, increase in fat tissue or loss of bone density, have not yet been clarified.

For weak patients, the treatment can begin with light stretching or gymnastic session of $10 \mathrm{~min}$. The level of activity in the daily routine can be increased step by step. Every form of exercise has advantages. However, the consequences of certain treatments and operations have to be taken into consideration, for example shoulder problems after breast amputation or lymph node resection. These patients should be treated with physical therapy if required [48]. If certain exercises or sports cause problems, then either the intensity should be reduced or other exercise types should be tried. If anemia or thrombocytopenia occur, it is best to stop until cured. In the case of reduced immune function, public sports facilities should be avoided. Care is recommended in the case of lymphedema and metastases.

Visiting special rehabilitation exercise groups is recommended, either integrated in organized sports or in the form of selfhelp groups. This helps to ease worries and enable the patients to meet the excessive demands their situation puts upon them. Since the beginning of the 1980s, about 650 exercise groups have been formed in Germany who can be contacted via the Landessportbund NRW (www.lsb-nrw.de) or the German Cancer Society (www.dkg.de).

Although a final statement regarding best type, intensity, duration and frequency of exercise cannot be given, existing data suggest the importance of physical activity in the prevention of and rehabilitation after breast cancer. Further data with a focus on study quality (prevention) and standardized training protocols (rehabilitation) are warranted. 


\section{References}

1 IARC Working Group on the Evaluation of Cancer-Preventive Agents: Weight Control and Physical Activity. IARC Handbooks of Cancer Prevention, vol 6. Lyon, IARC, 2002

2 Cherry T: A theory of cancer. Med J Aust 1922;1: 425-438.

3 Sivertsen I, Dhalstrom AW: The relation of muscular activity of carcinoma.: a preliminary report. J Cancer Res1922;6:365-378.

4 Friedenreich CM: Physical activity and cancer prevention: from observational to intervention research. Cancer Epidemiol Biomarkers Prev 2001; 10:287-301.

5 Evenson KR, Stevens J, Cai J, Thomas R, Thomas $\mathrm{O}$ : The effect of cardiorespiratory fitness and obesity on cancer mortality in women and men. Med Sci Sports Exerc 2003;35:270-277.

6 6 Blair SN, Kohl HW 3rd, Paffenbarger RS Jr, Clark DG, Cooper KH, Gibbons LW: Physical fitness and all cause mortality. A prospective study of healthy men and women. JAMA 1989;262:2395-2401.

7 Pinto BM, Maruyama NC: Exercise in the rehabilitation of breast cancer survivors. Psychooncology 1999;8:191-206.

8 Holmes M, Chen WY, Feskanich D, Kroenke CH, Colditz GA: Physical activity and survival afte breast cancer diagnosis. JAMA 2005;293: 2479-2486.

9 Caspersen CJ: Physical activity epidemiology: concepts, methods and application to exercise science. Exerc Sports Sci Rev 1989;17:423-473.

10 Byers T, Nestle M, McTiernan A, Doyle C, CurrieWilliams A, Gansler T, Thun M: American Cancer Society guidelines on nutrition and physical activity for cancer prevention: reducing the risk of cancer with healthy food choice and physical activity. CA Cancer J Clin 2002;52:92-119.

11 Friedenreich CM, Orenstein MR: Physical activity and cancer prevention: etiologic evidence and biological mechanisms. J Nutr 2002;132:3456-3464.

12 Albanes D, Blair A, Taylor PR: Physical activity and risk of cancer in the NHANES I population. Am J Public Health 1989;79:744-750.

13 Rockhill B, Willett WC, Hunter DJ, Manson JE, Hankinson SE, Colditz GA: A prospective study of recreational physical activity and breast cancer risk. Arch Intern Med 1999;159:2290-2296.

14 Lee IM, Rexrode KM, Cook NR, Hennekens CH, Burin JE: Physical activity and breast cancer risk: the Women's Health Study (United States). Cancer Causes Conrtol 2001:12:137-145.

15 Thune I, Brenn T, Lund E, Gaard M: Physical activity and the risk of breast cancer. N Engl J Med 1997:336:1269-1275.

16 Steindorf K, Schmidt M, Kropp S, Chang-Claude J Case-control study of physical activity and breast cancer risk among premenopausal women in Germany. Am J Epidemiol 2003:157:121-130.
Rintala P, Pukkala E, Läärä E, Vihko V: Physical activity and breast cancer risk among female physical education and language teachers: a 34-year follow-up. Int J Cancer 2003;107:268-270.

18 Frisch RE: Body fat, menarche, fitness and fertility. Hum Reprod 1987;2:521-533.

19 Woods JA: Exercise and resistance to neoplasia. Can J Physiol Pharmacol 1998;76:581-588.

20 Stoll BA: Adiposity as a risk determinant for postmenopausal breast cancer. Int J Obes 2000;24: 527-533.

21 Ballard-Barbash R: Anthropometry and breast cancer. Cancer 1994:74:1090-1100.

22 Hankinson SE, Willett WC, Manson JE, Colditz GA, Hunter DJ, Spiegelman D, Barbieri RL, Speizer FE: Plasma sex steroid hormones and risk of breast cancer in postmenopausal women. J Natl Cancer Inst 1998;90:1292-1299.

23 Hankinson SE, Willett WC, Colditz GA, Hunter DJ, Michaud DS, Deroo B, et al.: Circulating concentrations of IGF1 and risk of breast cancer. Lancet 1998;351:1393-1396.

24 Ng EH, Ji CY, Tan PH, Lin V, Soo KC, Lee KO: Altered levels of IGF binding proteins in breast cancer patients. Ann Surg Oncol 1998;5:194-201.

25 Kaaks R, Lukanova A, Kurzer MS: Obesity, endogenous hormones, and endometrial cancer risk: a systematic review. Cancer Epidemiol Biomarker Prev 2002;11:1531-1543.

26 Proietto J, Filippis A, Nakhla C, Clark S: Nutrient induced insulin resistance. Mol Cell Endocrine 1999;151:143-149.

27 Rose DP, Goldman M, Connolly JM, Strong LE: High fiber diet reduces serum estrogen concentrations in premenopausal women. Am J Clin Nutr 1991;54:520-525.

28 Thissen JP, Ketelslegers JM, Underwood LE: Nutritional regulation of the insulin-like growth factors. Endocr Rev 1994;15:80-101.

29 Lovejoy J, DiGirolamo M: Habitual dietary intake and insulin sensitivity in lean and obese adults. Am J Clin Nutr 1992:55:1174-1179.

30 Pedersen BK, Ullum H: NK cell response to physical activity: possible mechanisms of action. Med Sci Sports Exerc 1994;26:140-146.

31 Lee IM: Exercise and physical health: cancer and immune function. Res Q Exerc Sport 1995;66: 286-291.

32 Nieman DC: Exercise, upper respiratory infection, and the immune system. Med Sci Sports Exerc 1994;26:128-139.

33 Woods JA, Davis JM, Mayer EP, Ghaffar A, Pate RR: Exercise increases inflammatory macrophage cytotoxity. J Appl Physiol 1993;75:879-886.

34 McNeely ML, Campbell KL, Rowe BH, Klassen TP, Mackey JR, Courneya KS: Effects of exercise on breast cancer patients and survivors: a systematic review and meta-analysis. CMAJ 2006;175:34-41.
Dimeo FC: Körperliche Aktivität und Krebs - eine Übersicht. Dtsch Z Sportmed 2001;52:238-244.

36 Courneya KS, Friedenreich CM: Physical exercise and quality of life following cancer diagnosis: a literature review. Ann Behav Med 1999;21:171-179.

37 Schmitz KH, Holtzman J, Courneya KS, Masse LC, Duval S, Kane R: Controlled physical activity trials in cancer survivors: a systematic review and metaanalysis. Cancer Epidemiol Biomarkers Prev 2005; 14:1588-1595.

38 Dimeo F, Fetscher S, Lange W, Mertelsmann R, Keul J: Effects of aerobic exercise on the physical performance and incidence of treatment-related complications after high-dose chemotherapy. Blood 1997;90:3390-3394.

39 Irwin ML, Ainsworth BE: Physical activity interventions following cancer diagnosis: methodologic challenges to delivery and assessment. Cancer Invest 2004;22:30-50.

40 Thorsen L, Skovlund E, Stromme SB, Hornslien K, Dahl AA, Fossa SD: Effectiveness of physical ac tivity on cardioraspiratory fitness and health-related quality of life in young and middle-aged cancer patients shortly after chemotherapy. J Clin Onco 2005;23:2378-2388.

41 Thune I, Smeland S: Is physical activity important in treatment and rehabilitation of cancer patients? Tidsskr Nor Laegeforen 2000;120:3302-3304.

42 McTiernan A: Physical activity after cancer: physiological putcome. Cancer Invest 2004;22:68-81.

43 Lee IM, Oguma Y: Physical activity; in Schottenfeld D, Fraumeni JF Jr (eds): Cancer Epidemiology and Prevention, ed 3rd. San Fransisco, Oxford University Press, 2006

44 Eyre H, Kahn R, Robertson RM; American Cancer Society, the American Diabetes Association, and the American Heart Association Collaborative Writing Committee: Preventing cancer, cardiovascular disease, and diabetes: a common agenda for the American Cancer Society, the American Diabetes Association, and the American Heart Association. Diabetes Care 2004:27:1812-1824.

45 Lee IM, Paffenbarger RS, Hsieh C: Physical activity and risk of developing colorectal cancer among college alumni. J Natl Cancer Inst 1991;83: 1324-1329.

46 Marrett LD, Theis B, Ashbury FD: Workshop report: physical activity and cancer prevention. Chronic Dis Can 2000;21:143-149.

47 Brown JK, Byers T, Doyle C, Courney KS, Demark-Wahnefried W, Kushi LH, et al.: Nutrition and physical activity during and after cancer treatment: an American Cancer Society guide for informed choices. CA Cancer Clin J 2003;53:268-291.

48 Neff MJ: ACS releases guidelines on nutrition and physical activity during and after cancer treatment. Am Fam Phys 2004;69:1803-1805. 